\title{
Universal Health Coverage at the Macro Level: Synthetic Control Evidence from Thailand
}

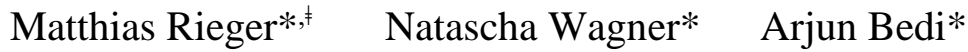 \\ September 5, 2016 \\ *Institute of Social Studies (ISS), Erasmus University, The Netherlands \\ ${ }^{\ddagger}$ Corresponding author: ISS, Kortenaerkade 12, 2518 AX Den Haag, Netherlands; +31 70426 0553; \\ rieger@iss.nl
}

\begin{abstract}
We use synthetic control methods to study the impact of Universal Health Coverage (UHC), introduced in Thailand in 2001, on various macroeconomic outcomes. Thailand is compared to a weighted average of control countries in terms of aggregate health financing indicators, aggregate health outcomes and economic performance, over the period 1995 to 2012. Our results suggest that UHC helps alleviate the financial consequences of illnesses. The impact of UHC on out-of-pocket payments as a percentage of overall health expenditures is 13 percentage points and its impact on annual government per capita health spending is US\$ 79. We detect a smaller impact of US\$ 60.8 on total health spending per capita which appears with a lag. We document positive health impacts as captured by reductions in infant and child mortality. We do not find any impact on GDP and the share of the government budget devoted to health. Overall, our results complement micro evidence based on within country variation. The counterfactual design implemented here may be used to inform other countries on the macro level repercussions of UHC.
\end{abstract}

Keywords: Universal Health Coverage, Macro Impacts, Synthetic Control Approach, Thailand 


\section{Introduction}

This paper examines the impact of universal health coverage (UHC) in Thailand on aggregate health financing indicators, GDP per capita and child and infant mortality rates. The focus on health financing indicators and child and infant mortality is motivated by the WHO which argues that the provision of accessible and qualitatively effective health care for all and protection against financial hardship, are core elements of UHC (WHO, 2015). At the same time we also examine the effect of introducing UHC on economic performance as it has been argued that reduced out-of-pocket expenditure spurs economic growth (Sachs, 2012). While there are many micro studies on the effects of UHC in developing countries (Limwattananon et al., 2015; Gruber et al., 2014; Miller et al., 2013; Wagstaff and Manachotphong, 2012; Barofsky, 2011), including Thailand, there is currently little causal evidence at the aggregate level. For policy makers, aggregate level information on the budgetary consequences of introducing UHC as well as the potential benefits of such a policy are likely to be important inputs in determining whether or not to implement UHC.

The WHO keenly advocates UHC as demonstrated by the 2013 World Health Report on universal health coverage. In 2009, only 58 countries were classified as having attained full UHC with Thailand being one of them (Stuckler et al., 2010). The country introduced the UHC policy, originally known as the 30 baht project, in 2001. Three different schemes are in place, including, two employment-based schemes and the tax-financed Universal Coverage Scheme. The nationwide roll-out of the Universal Coverage Scheme was completed within a year, reaching a coverage of 71\%. Coverage increased to 95\% in 2003, and 98\% by 2011 (International Health Policy Program, 2011). Health care coverage was extended to 18.5 million uninsured people out of a population of 62 million (Townsend et al., 2004). The benefit package for the insured includes inpatient and outpatient care at accredited facilities as well as access to 
prescribed medication.

In the case of Thailand, existing micro evidence documents reductions in out-of-pocket payments and improved financial protection due to UHC (for instance, see Limwattananon et al., 2015; Gruber et al. 2014). While these papers provide useful evidence on the financial impact of the UHC scheme at the household level, for policymakers it is important to know the financing implications of introducing UHC and the impact on an entire economy. Capturing aggregate effects is not straightforward and the literature is often restricted to papers that rely on micro data which may not always support generalization to the aggregate level. MorenoSerra and Smith (2015) is a notable exception. They assess the macroeconomic impacts of universal health coverage at the global level. The study estimates the effects of health coverage for a large panel of 153 countries over the period 1995 to 2008 by means of an instrumental variables approach to account for reverse causality. They find that expanding health care coverage improves population health as captured by reductions in child and adult mortality. Higher government health spending drives the reductions in mortality rates. Courtemanche and Zapata (2014) evaluate the impact of universal health coverage on various health indicators following a 2006 reform in Massachusetts. Among other empirical strategies, they use synthetic control methods.

Establishing a credible counterfactual, that is, identifying what would have happened in case UHC had not been introduced, is difficult. In this paper, we use synthetic control methods (Abadie et al., 2010) to compare Thailand to a plausible group of control countries without UHC. We construct the counterfactual outcome for Thailand as a weighted linear combination of control countries. The pool of controls consists of countries without UHC in the Asia and Pacific region. The weights are chosen so that the differences between Thailand and the control 
countries are minimized in terms of pre-treatment average outcomes and other observable characteristics. For every outcome variable we construct a separate synthetic Thailand since the relative influence of observable and unobservable characteristics is likely to differ across outcomes. This approach offers a data-driven way of finding an optimally weighted average of control countries so that they track Thailand in terms of outcomes of interest prior to UHC. The resulting "synthetic" Thailand is then used to simulate the country's hypothetical trajectory in the absence of UHC. Our goal is to assess whether some of the observed changes in aggregate variables in Thailand may be attributed to the implementation of UHC, net of general trends for Thailand and its regional neighbors. At the aggregate, we carefully need to check whether the control, that is, the synthetic Thailand is a valid counterfactual which displays the outcome trajectory Thailand would have had in the absence of the introduction of UHC. The tighter the pre-treatment fit between Thailand and the control the more likely it is that we can reproduce what would have been observed for Thailand in the absence of UHC. In addition, we compare the results from the synthetic control approach with those obtained by employing a differencein-difference model since the former is a generalization of the latter (Abadie et al., 2010).

Based on the synthetic control model, where impact is defined as the average difference between the post-treatment outcomes for Thailand and the synthetic Thailand, averaged over twelve post-treatment years, we find that UHC has -13 percentage point effect on out-of-pocket expenditure as a share of total expenditure and the impact on government per capita health spending is US\$ 79.0. There is a smaller impact of US\$60.8 on total per capita health spending which appears with a lag. We do not find any impact on the share of the government budget share allocated to health. Similarly, there is no evidence that the introduction of UHC has harmed the economic performance of Thailand, as measured by GDP, vis-à-vis other countries in the region. While we do not have time series data on health seeking behavior, we examined 
mortality data at the national level. Post-UHC, aggregate infant and child mortality in Thailand is approximately $20 \%$ lower as compared to the synthetic Thailand.

The remainder of the paper is structured as follows. Section 2 is divided into three parts. The first subsection presents the data sources and defines the outcome indicators. The second subsection outlines the two empirical approaches, that is, the synthetic control approach and the difference-in-difference model. The last sub-section discusses the composition of the control group and compares pre-treatment differences between Thailand and the control countries/synthetic control. Section 3 presents the results and related robustness tests. Section 4 discusses the findings and compares them with evidence based on micro-data. Section 5 concludes.

\section{Methods}

\section{Data sources and definition of outcome indicators}

Our analysis covers the period 1995 to 2012 and relies on data from three sources. We use data from the World Health Organization's Global Health Observatory to assess the impact of universal health coverage on several health-spending indicators. To assess the impact of the policy on financial protection we use out-of-pocket expenditures as a percentage of total health expenditures, which does not include regular insurance payments. Existing evidence indicates that high out-of-pocket payments are strongly related with catastrophic health spending and impoverishment (Chuma and Maina, 2012; Ghosh, 2011; Yardim et al., 2010; Xu et al., 2007). A complementary expenditure category is government expenditure on health as a percentage of total health expenditure. To achieve financial protection against catastrophic health spending, government spending needs to increase correspondingly. In many developing countries, including Thailand, out-of-pocket payments and government health expenditure are the major 
components of total expenditure on health. The residual category includes private insurance programs and contributions to health care financing from charities. We also consider total health expenditures per capita and government health expenditure per capita. Finally, we consider another core indicator of health financing systems which is government expenditure on health as a percentage of the total budget.

Due to the potential link between health expenditure and economic growth, in addition to the impact of UHC on health spending we examine its impact on GDP per capita (PPP, constant US \$2005). Since UHC is not just about financial protection but also the provision of accessible care of sufficient quality for all (WHO, 2015), we also study its impact on infant and child (under-five) mortality. The data were obtained from the World Bank's World Development Indicators (using the "wbopendata” command in STATA) and the UN Inter-Agency Group for Child Mortality Estimation, respectively. The mortality data is in part based on simulations and estimates have to be interpreted with this caveat in mind. Infant mortality is defined as the number of infants dying before reaching one year of age, per 1,000 live births in a given year. Child mortality refers to the death of infants and children before reaching the age of five per 1,000 live births. These mortality estimates are widely used and have already been analyzed in panel settings (Moreno-Serra and Smith, 2015) and with the synthetic control method (Pieters et al., 2014). All three data sources use the same definitions across countries and the countrylevel information has been harmonized by the agencies providing the data in order to support international comparisons.

\section{The synthetic control method}

To analyze the impact of UHC on the evolution of annual health spending, the overall performance of the economy and child mortality rates, we compare Thailand's performance 
with outcome-specific synthetic control groups. These synthetic control groups are composed of a weighted average of countries in the Asia and Pacific region without universal health care coverage.

The method is a predominantly data-driven way of determining a counterfactual which allows for causal estimates in contexts with only one treated unit and a few control countries (Abadie et al., 2010). The method uses numerical optimization to create a weighted average of the control countries such that differences in pre-treatment outcomes and observed pre-treatment confounders (specified by the researcher) between the treated and synthetic control unit are minimized. The method allows the effect of observed and unobserved confounders that may affect the outcome to change over time. Subsequently, the computed weights, which are nonnegative and sum to one, are applied to post-treatment outcomes in the control units to simulate Thailand's hypothetical path in the absence of UHC. If a good pre-treatment fit between Thailand and its synthetic control is achieved, then differences in post-treatment outcomes may plausibly be attributed to the universal health care policy of the country (for additional details see Abadie and Gardeazabal, 2003; Abadie et al., 2010; Abadie et al., 2011; Donohue and Aneja, 2012; Billmeier and Nanncini, 2013; and Fremeth et al., 2013).

The approach imposes a linear relationship between the outcomes and the confounders and an additive form of the unobserved confounders. Only if the number of pre-treatment periods is large relative to the size of the unobserved confounders an approximately unbiased estimator of the treatment effect can be obtained since a close match of the pre-treatment outcomes makes it more plausible that unobserved confounders are also similar over time between the treated and the synthetic control groups. The eligible control countries need to remain unexposed to the intervention throughout the period under study. 
Due to the small sample, classical tests of statistical significance cannot credibly be applied to the synthetic control method. However we can gauge significance using pseudo $p$-values based on exact inference or permutation (Fremeth et al, 2013; Rosenbaum 2002a, 2002b). To judge the statistical significance of the observed impacts we falsely assign the policy one-by-one to all the countries in the pool of control countries. Then, the difference in outcomes between the country to which the intervention was falsely attributed, and the synthetic control is calculated yielding a placebo treatment effect. This approach allows us to assess whether the treatment effect for Thailand is large relative to the estimated placebo effects. In addition to the visual inspection, we calculate ratios of post to pre-intervention root mean squared prediction errors (RMSPE) for all placebos and Thailand. The RMSPE is the root of the average squared difference between the (placebo) treated country and the weighted average of control countries. The logic behind the ratio is that a relatively large difference between treatment and control after the intervention as compared to before indicates statistical significance. We then rank the RMSPEs and calculate pseudo $p$-values.

\section{The difference-in-difference method}

Since the synthetic control method is a generalization of a conventional difference-in-difference method, we compare the estimates obtained from the synthetic control method with those using difference-in-difference regressions. In this case, the outcomes in Thailand are compared to a set of control countries before and after the intervention. The estimated treatment effect is obtained by subtracting the pre-intervention difference from the post-intervention difference. Unlike the synthetic control method each control country in the difference-in-difference approach has the same weight and it is assumed that the effect of unobserved confounders is time-invariant and may be eliminated by differencing the data. The approach also assumes that the treatment and control group are equally affected by changes that occur over time implying 
that in the absence of the intervention the treated and the control countries would have had parallel trajectories. As an additional robustness check we use weights generated from the synthetic control approach and estimate weighted difference-in-difference models, potentially removing remaining pre-treatment differences.

\section{Composition of the control group and descriptive statistics}

A pool of 17 countries in the Asia and Pacific region was used to create the synthetic control unit (see Appendix, Table A.T1). These control countries do not have universal health coverage and the required macroeconomic data are available for a period of six years before and 12 years after the UHC reform in Thailand, that is, 1995 till 2012.

We carefully constructed the pool of control countries in the region and excluded outliers or contaminated controls as advised by Abadie et al. (2010). We excluded developed countries (Japan and Australia). Two countries leave the sample due to missing data (Myanmar and Timor-Leste). We also dropped countries with health financing systems that are (nearly) universal or are moving towards universal health coverage (Minh et al., 2014; Asian Development Bank, 2011; Somanathan and Hafez, 2010; Rannan-Eliya and Sikurajapathy, 2009). These countries are Malaysia, Palau, Sri Lanka, and Tonga. Finally, we excluded the special cases of India and China from the analysis, as they are considerably larger in geographical size, have populations that are about 18 times larger than Thailand, and generate a volume of GDP (in 2005 PPP) that is at least 7.5 times higher.

For each outcome variable we create a separate synthetic Thailand. This approach is similar to other studies that have used synthetic control methods with multiple outcomes (Quast and Gonzalez, 2016; Fletcher et al., 2015; Bohn et al., 2014; DeAngelo and Hansen, 2014; Bove and Elia, 2014). Since, the synthetic control method permits (i) matching on the pre-treatment 
outcome variable and (ii) on additional observed pre-treatment confounders specific to every outcome as well as (iii) matching one control group for all outcomes, we present two sets of estimates. In the first model (main) we match on the pre-treatment outcome variable and a set of pre-treatment control variables. We include the following variables: per capita GDP (log), total population, share of population under 14 years of age, a subset of the health expenditure variables and infant mortality (log). We do not include both infant and child mortality since the two indicators are highly correlated. We include total health expenditure per capita, out-ofpocket expenditure as a share of total health expenditure, and government health expenditure as a share of total health expenditure. In the second specification (basic) we match Thailand to the set of control countries only on the basis of the pre-treatment outcome variable.

While it is common practice to fit a separate synthetic control for each outcome, as a robustness check, we also examined the effect of fitting one synthetic control to all outcomes. We applied the synthetic control weights from our main financing outcome (out-of-pocket expenditures), as well as the health outcome (infant mortality) to all other outcomes. Finally, we also averaged the weights across all outcomes and then calculated impact.

Table 1 presents descriptive statistics. In terms of magnitude, a simple unweighted comparison of pre-treatment means between Thailand and the entire group of control countries indicates poor balancing at baseline (compare columns 1 and 2). Out-of-pocket expenditure as a share of total health expenditures is 5.6 percentage points higher in Thailand as compared to the control countries and government health expenditure as a share of total health expenditure is almost 10 percentage points lower. Total and government health expenditure per capita are both considerably higher in Thailand as compared to the control countries. In contrast, pre-treatment means between Thailand and the synthetic control are well balanced across outcomes. Across 
all outcomes and regardless of the approach used to create the synthetic control (main vs. basic), differences in pre-treatment means are close to zero. In other words, the synthetic control for every outcome variable resembles the situation in Thailand before the introduction of UHC.

\section{Results}

The impact of UHC using the synthetic control method: Main model

This section discusses the impacts of UHC, defined as the difference between the post-treatment outcomes for Thailand and the synthetic Thailand, averaged over the post-treatment years, on various outcomes. Panel A of Table 2 presents these impact estimates based on the main synthetic control model. We graph the outcome trajectories of Thailand, the synthetic Thailand and a simple average of the control countries in the left-hand column of Figures 1 and 2. In the right-hand column of Figures 1 and 2, we present the yearly difference between Thailand and its synthetic control (in bold). For a good fit prior to the treatment in 2001, we expect the difference line to be tightly aligned around zero. If this is the case then the annual post-treatment differences may be interpreted as year-by-year causal impacts. If pre-treatment differences are large, we cannot credibly attribute post-treatment differences to UHC. If UHC has an impact then after 2001 we expect the post-treatment lines to deviate considerably from zero.

In the right-hand column of Figures 1 and 2 we also plot differences based on placebo models where we falsely assign the policy one-by-one to all the other countries in the pool of control countries resulting in 17 pseudo-treatments. The differences in outcomes between the synthetic control and country to which treatment is falsely attributed are presented in grey. This allows us to gauge if differences in post-treatment (treatment effects) Thailand stand out relative to the placebo cases.

We start with the results for out-of-pocket expenditures. Before the policy, the indicator tracks 
its synthetic counterfactual reasonably well (Figure 1, Panel A). The differences between the two trajectories (Thailand and synthetic Thailand) are small relative to the differences we observe after the introduction of UHC (Figure 1, Panel B). In particular after 1997 the difference is concentrated around the zero line. Following UHC, this difference becomes negative and increases over the years. The average annual difference, that is the average impact of UHC, is -13 percentage points (Table 2, Panel A). Furthermore, the post-intervention difference in the trajectory of out-of-pocket expenditures between Thailand and its synthetic counterpart, especially after 2006, stands out relative to the placebo models (Figure 1, Panel B). The pseudo $p$-value corresponding to the average effect is $11 \%$. Since the pseudo $p$-value is based on only 18 observations (Thailand plus 17 control countries) classical critical values are not applicable. The $p$-values are obtained from the ranking of the RMSPEs. If for example, Thailand is ranked first, the chance of this is $1 / 18$ or a $p$-value of $6 \%$. Moving down just one rank, yields $2 / 18$ or a $p$-value of $11 \%$. UHC has a positive impact on government health spending as a percentage of total health expenditure. Over the post-treatment period, the average difference between Thailand and its synthetic control is 15.5 percentage points (Table 2, Panel A; Figure 1, Panel C) and the pseudo $p$-value is $17 \%$. Figure A.F1 in the appendix presents the ranking of the RMSPEs corresponding to the placebo tests and resulting pseudo $p$-values. The placebo assignment suggests that, in particular after 2003, almost no country in the control group shows similar differences with respect to its synthetic control as Thailand over the post-treatment period (Figure 1, Panel D). In other words, the annual treatment effect on government health expenditure as a share of total health expenditures in Thailand is higher than the placebo treatment effects estimates for other countries.

Consistent with the impact on out-of-pocket expenditure, there is a positive impact of UHC on per capita government health expenditures. Before treatment, Thailand and its synthetic control 
follow similar trends (Figure 1, Panel E). The year-by-year differences are close to zero indicating good pre-treatment fit (Figure 1, Panel F). The average impact of UHC amounts to US\$ 79 per year over the post-intervention period with a pseudo $p$-value of 11\% (Table 2, Panel A). As shown in Panels E and F of Figure 1, over time, the treatment effect grows in magnitude. The impact on per capita government health expenditures is larger than the impact on total per capita health expenditures. On average, the latter amounts to US\$ 60.8 over the post-treatment period (Table 2, Panel A; Figure 1, Panel G). The associated pseudo $p$-value is $11 \%$. The difference between Thailand and its synthetic control trajectory is small prior to UHC and is larger after the introduction of UHC (Figure 1, Panel H). Moving to the share of the government budget allocated to health, the post-treatment average difference is 2.2 percentage points (Table 2, Panel A). The pseudo $p$-value is 0.28 . The synthetic Thailand does not track Thailand well before treatment (Figure 2, Panels A and B). In other words, there is a poor pre-treatment fit and given the set of control countries and the limited amount of pre-intervention data we are unable to establish a good counterfactual.

We next consider the impact of UHC on GDP per capita. Panels C and D of Figure 2 suggest that Thailand does not track its synthetic counterfactual well before the introduction of UHC. Several placebo models show a much tighter pre-treatment fit as indicated by smaller differences between treatment and control. After UHC, we see positive differences materializing in Thailand relative to its synthetic control. The average treatment effect has a pseudo $p$-value of 0.28 indicating that in terms of RMSPE, Thailand ranks $5^{\text {th }}$ out of 18 countries. Given the data at hand we are unable to establish a good counterfactual. As shown in Panel A, Table A.T1, all the weight is given to a single country. Nevertheless, the results do suggest that UHC has not had a negative effect on GDP per capita. 
Turning to the effect of UHC on health outcomes, we see in Panel E of Figure 2 that there is a steady decline in infant and child mortality over the study period. The impacts of UHC on infant and child mortality are -19 and $-21 \%$, respectively (Figure 2, Panels E and G; Table 2, Panel A). The pre-treatment difference is small relative to the post-treatment difference. The corresponding pseudo $p$-values are 11\% (Figure 2, Panels F and H).

Robustness check - assessing the impact of UHC using a basic synthetic control model Our main model specification does not make full use of all control countries. Only a handful of countries receive non-zero weights in constructing the synthetic control (Panel A, Table A.T1 in the Appendix). While the model leads to considerable improvement in balance across baseline characteristics compared to the unweighted averages, differences between Thailand and the synthetic Thailand remain (Table A.T2). Since we only have 17 control countries balancing on many dimensions is not always feasible. Therefore, we also estimate a basic model where we only match on the pre-treatment trend of the outcome variable. Results are presented in Panel B of Table 2 and Figures are provided in the Appendix (A.F2, A.F3 and A.F4). With the exception of the GDP per capita model, all available control countries are now assigned a non-zero weight in the basic model and the weights are well distributed with no single country dominating (Panel B, Table A.T1). Moreover, the pre-treatment difference in the outcome variables is closer to zero than in the main model for all eight outcomes under study (Table A.T2).

Results are reasonably stable across models. The basic model shows that the difference between observed and counterfactual post-treatment outcomes in out-of-pocket spending is negative following the introduction of UHC (Figure A.F2, Panel A). The impact is -15.5 percentage points with a pseudo $p$-value of $11 \%$ (Table 2, Panel B) compared to -13.0 ( $p$-value=0.11) in 
the main model while the impact on government health expenditures as share of total health expenditures is 17.7 percentage points with a pseudo p-value of $11 \%$ as compared to 15.5 (pvalue $=0.17$ in the main model. The results also show that UHC has a positive impact on per capita government health expenditures. However, the estimated average difference between Thailand and its synthetic control is less pronounced as compared to the main model (see column 3 in Table 2). With regard to total per capita health expenditures, we document a much smaller effect and a higher $p$-value (Table 2, Panel B). Consistent with the main model, we find that the introduction of UHC does not have an impact on the government budget allocated to health nor on GDP per capita and the impact of UHC on infant and child mortality remains at about $-20 \%$. However at least the former model suffers from relatively poor pre-treatment fits and we do not want to over-interpret impact estimates and associated $p$-values.

Robustness check - assessing the impact of UHC using one synthetic control for all outcomes While it is common practice to fit a separate synthetic control for each outcome, we also examined the effect of fitting one synthetic control to all outcomes. To this end, and in order to cover both the financial and health outcomes, we use the weights from our main financing variable (out-of-pocket expenditures; Table A.T1, Panel A, Column 1) as well as one health indicator (infant mortality; Table A.T1, Panel A, Column 7). The results are presented in the appendix in Table A.T3 and Figure A.F5. Figure A.F5 shows that the pretreatment fit is considerably weaker when matching is not done relative to the outcome under study. We obtain a reasonably close fit for government health expenditures (as share of total health expenditures) with weights from out-of-pocket expenditures, which is attributable to the high (negative) correlation among these variables. A similarly good fit is obtained for child mortality using infant mortality weights. However, the fit between the child health outcomes using weights from out-of-pocket health expenditures, and vice versa, is poor. With these caveats in mind, 
except for one outcome, the impact estimates are qualitatively in line with the findings from the main model (compare Table 2, Panel A with Panel B and C of Table A.T3). When we use the out-of-pocket weights we tend to overestimate the impact of UHC on the health financing variables while the use of the infant mortality weights leads to smaller impact estimates for the health financing outcomes. Finally, we also calculated impacts by applying the average weights from the main model across all outcomes (row average of Table A.T1, Panel A, Columns 1-8). These impact estimates are qualitatively similar to those obtained using the main model, although they tend to be smaller for the health financing outcomes and larger for the mortality related outcomes (Table A.T3, Panel D).

While we have provided estimates based on one synthetic control across all outcomes, the patterns in Figure A.F5 suggest that the pre-treatment trend and underlying data generating processes vary across outcomes and that the optimal weights for financing and health variables need to be different to ensure better pre-treatment balance. We are also limited by the small set of control countries while having to balance on several outcome variables and covariates. A larger pool may have yielded more stable weights across outcomes.

\section{Robustness checks using a difference-in-difference model}

We also estimated the average impact of UHC on all outcomes using difference-in-difference models (Table 3). Since the standard errors of the models presented in this table are based on one treatment country and 17 control countries (Panel A) and on one treatment country, and for some outcomes, a smaller set of control countries (Panels B and C), standard errors have to be interpreted with caution.

In the difference-in-difference models we include country and year-specific effects, the total 
population and the share of the population under 14 years of age. Estimates in Table 3, Panel A are based on a regression model giving equal weights to all the countries in the sample. The impacts of UHC are -15.8 percentage points and 18.2 percentage points on out-of-pocket expenditure and on government health expenditures as a percent of total health expenditures, respectively. The impact on per capita government health expenditure is US\$ 56.2, while there is a more modest impact of US $\$ 32.3$ on total per capita health expenditure. These effects, especially for out-of-pocket expenditure and government health expenditure as a share of total health expenditures locate in the same range as those based on the synthetic control models. Similar to the estimates based on the synthetic control approach, there is no significant impact on government health expenditure as a share of total government spending or on GDP per capita. The statistically significant treatment effects on infant and child mortality are -15 and 13 percentage points, respectively.

In Panel B of Table 3 we present difference-in-difference estimates based on applying the country weights obtained from the synthetic control main model approach. Panel C of the same table provides estimates based on the weights from the synthetic control basic model. The motivation of these "hybrid" models is that after weighting, the difference-in-difference approach can potentially remove remaining pre-treatment differences. Depending on the weights used, the average treatment effects associated with UHC are -9 or -15 percentage points in the case of out-of-pocket expenditures, as well as 12.8 or 17.6 percentage points in the case of government expenditures as a percent of total health expenditures. The impact on government health expenditure per capita ranges between US\$ 52.1 and US\$ 68.5. Consistent with estimates based on the synthetic control methods, increases in total health expenditures are smaller and there is no effect on the share of the government budget spent on health. However, unlike estimates based on the synthetic control method, the effects on infant and child 
mortality are considerably smaller and statistically insignificant.

\section{Discussion}

Regardless of whether we rely on the main or the basic specification of the synthetic control approach, we interpret the estimates in that the introduction of UHC in Thailand has resulted in increased financial protection by shifting the burden of costs from individuals to the state. This shift seems to have occurred without an impact on the share of the public budget spent on health care. Whether these are causal effects depends on the extent to which the assumptions of the synthetic control approach are satisfied. While this paper provides new causal evidence at the macro level, the analysis suffers from three main limitations: First, the creation of the synthetic control unit was based on only six years of pre-intervention information since data prior to 1995 was unavailable. Second, we only have a set of 17 control countries from the region. At the same time, we needed to balance pre-treatment characteristics along several dimensions. As a result some pre-treatment co-variates such as GDP and population size are not always wellbalanced (Table A.T2). Although, in most instances, the differences based on the synthetic control approach tend to be smaller than the unweighted difference. Moreover, Figures 1 and 2 show that there are differences in the quality of the match across the various pre-treatment outcomes. Clearly, the match for government health expenditure as a share of the total government budget is not as tight as for total per capita health expenditures. Third, while we find consistent impacts of UHC on the mortality variables, in part, the mortality data are simulated and exhibit stable downward trends over the pre- and post-treatment period which raises doubts about a UHC induced impact.

As a robustness check we also examined the effect of UHC using a difference-in-difference approach which relies on different assumptions to identify a causal effect. The size and 
significance of the estimates were qualitatively similar to those based on the synthetic control approach. In sum and despite the above mentioned limitations, there is evidence that UHC in Thailand has enhanced financial protection.

A pertinent question arising from the estimates of UHC on the various health expenditure outcomes is whether they reveal any evidence of efficiency gains which may be attributed to the scheme. The estimates indicate that out-of-pocket expenditures and government health expenditures as a share of total health expenditures are close substitutes. At the same time we find that the impact on government health expenditure per capita is larger than the impact on total health expenditure per capita, indicating lower per capita private expenditures on health. For instance, based on the estimates reported in Table 2, Panel A, we find that, on average, the annual impact of UHC on public health expenditure per capita is US\$ 79.0 while the impact on private health expenditure per capita is US\$ -18 , on average, per year. Based on this it would seem that the reform does not increase efficiencies in the procurement of health care services, but shifts expenditures from households to the government. At the same time we find a modest (1.32 to 2.16 percentage points) impact on average annual government health expenditures as a share of total government spending (which may in part be attributed to poor model fit). While we cannot directly assess whether there have been efficiency gains, our estimates suggest that a relatively small increase in the share of the budget allocated to health care expenditure may have been sufficient to reach UHC. More finely grained hospital and pricing data would be necessary to estimate possible efficiency gains.

In terms of health outcomes UHC has a negative effect on both infant and child mortality. While this is an appealing result, as pointed out earlier, the mortality data is in part based on simulations. Hence, trends and changes in trends have to be interpreted with this caveat in mind. 
Furthermore, the negative effect on out-of-pocket expenditure and the lagged effect on total health expenditure does raise skepticism about a UHC-driven decline in mortality. However, theoretically this is possible. For instance, due to lower out-of-pocket expenditures, households may be more likely to have money available to spend on other consumption goods and services, some of which may benefit children (e.g. nutrition, time spent rearing children). Improvements in infant mortality could also be driven by the most vulnerable children, i.e. those born to low socio-economic status households. While prior to UHC infant mortality was higher in poorer provinces, this gap closes after the introduction of UHC suggesting that at the aggregate infant mortality was reduced by 2 per 1,000 births (Gruber at al., 2014). Regardless of this and other possibilities, we do not want to overstate the effect of UHC on the mortality outcomes.

In this respect, it would have been interesting to investigate the impact of UHC on a set of additional indicators such as health care utilization to capture demand for health services, government expenditure on education or other heads to expenditure in order to examine budgetary shifts, and on overall budget deficits to gauge fiscal sustainability. However, we were unable to find systematic and consistent time-series information for these indicators. Even the most comprehensive data sources such as the World Bank's World Development Indicators do not coherently report the required information.

Finally, our results may be compared with existing micro evidence. Based on household data, Limwattananon et al. (2015) show that the Thai UHC reform reduced out-of-pocket expenditures by 28\%. Similar evidence is reported for Mexico (Barofsky, 2011). With regard to health outcomes and health seeking behavior, previous micro studies have also reported positive impacts. For instance, the Thai UHC positively affects working age people by reducing the likelihood that they report themselves to be too sick to work (Wagstaff and Manachotphong, 
2012), it further increases the demand for outpatient services (Panpiemras et al., 2011), and preventive check-ups (Ghislandi et al., 2013). At the same time, there is no evidence that ex ante moral hazard is affected (Ghislandi et al., 2013). In addition, Gruber et al. (2014) show that infant mortality rates fell due to better access to health services among poor Thai. Clearly, our findings of a negative effect on out-of-pocket expenditure and infant mortality are similar to those based on these micro-studies. In addition, we provide new evidence on the impact of UHC on central government finances, aggregate health spending as well as on GDP.

\section{Conclusion}

By providing macroeconomic evidence on the impact of UHC this paper complements the existing microeconomic evidence on universal health coverage in the case of Thailand. While not beyond reproach, mainly due to data limitations, the synthetic control approach adopted in this paper showed that the UHC policy has led to a negative effect on out-of-pocket expenditures and a corresponding positive effect on government expenditure on health. Positive impacts on the share of the government budget allocated to health were modest and statistically insignificant. We were also unable to detect a statistically significant impact of UHC on GDP. We did find that UHC was associated with negative effects on infant and child mortality although data limitations preclude us from overstating this claim.

Evidence on the aggregate effects of UHC, especially on government finances is important from a policy perspective as low-income countries strive to introduce policies to reach UHC. This study is the first to provide causal evidence on the impact of UHC on government finances. A causal investigation of government finances is important as many low-income countries lack resources to guarantee universal coverage. In implementing UHC, policy makers have to jointly address three related objectives, namely (i) equity in access to health services, (ii) the quality 
of health services and (iii) financial-risk protection (WHO, 2015). However, these objectives

can only be achieved if a country has a sound health financing system in place (WHO, 2010).

The approach presented should be viewed as a complement to micro approaches and an arguably credible way of carrying out rigorous macroeconomic assessments of policies such as UHC.

\section{References}

Abadie, Alberto, Alexis Diamond, and Jens Hainmueller. 2010. Synthetic control methods for comparative case studies: Estimating the effect of California's tobacco control program. Journal of the American Statistical Association. 105(490): 493-505.

Abadie, Alberto, Alexis Diamond, and Jens Hainmueller. 2011. Comparative politics and the synthetic control method. MIT Department of Political Science Working Paper No. 2011-25.

Abadie, Alberto and Javier Gardeazabal. 2003. The economic costs of conflict: A case study of the Basque Country. American Economic Review. 93(1): 112-132.

Asian Development Bank. 2011. Sustainable health care financing in the Republic of Palau. Pacific Studies Series. Asian Development Bank, Mandaluyong City, Philippines.

Barofsky, Jeremy. 2011. Estimating the impact of health insurance in developing nations: Evidence from Mexico's Seguro Popular. Harvard School of Public Health, Cambridge, MA.

Billmeier, Andreas and Tommaso Nannicini. 2013. Assessing economic liberalization episodes: A synthetic control approach. Review of Economics and Statistics. 95(3): 983-1001.

Bohn, Sarah, Magnus Lofstrom and Steven Raphael. 2014. Did the 2007 Legal Arizona Workers Act reduce the State's unauthorized Immigrant Population? Review of Economics and Statistics. 96(2): 258-269.

Bove, Vincenzo and Leandro Elia. 2014. The impact of American and British involvement in Afghanistan and Iraq on health spending, military spending and economic growth. B.E. Journal of Macroeconomics. 14(1): 325-339.

Chuma, Jane and Thomas Maina. 2012. Catastrophic health care spending and impoverishment in Kenya. BMC Health Services Research, 12(413):1-9.

Courtemanche CJ, Zapata D. 2014. Does universal coverage improve health? The Massachusetts experience. Journal of Policy Analysis and Management 33: 36-69.

Damrongplasit, Kannika and Glenn A. Melnick. 2009. Early results from Thailand's 30 baht health reform: Something to smile about. Health Affairs 28(3): w457-w466.

DeAngelo, Gregory and Benjamin Hansen. 2014. Life and Death in the Fast Lane: Police Enforcement and Traffic Fatalities. American Economic Journal: Economic Policy. 6(2): 231-257.

Donohue III, John J. and Abhay Aneja. 2011. New evidence in the 'More Guns, Less Crime' debate: A synthetic controls approach. Working Paper.

Fletcher, Jason M., David E. Frisvold, and Nathan Tefft. 2015. Non-Linear Effects of Soda Taxes on Consumption and Weight Outcomes. Health Economics 24(5): 566-582.

Fremeth, Adam R., Guy L. F. Holburn and Brian Kelleher Richter. 2013. Making causal inferences in small samples using synthetic control methodology: Did Chrysler benefit 
from government assistance? Working Paper.

Galárraga, Omar, Sandra G. Sosa-Rubí, Aarón Salinas-Rodríguez and Sergio Sesma-

Vázquez. 2010. Health insurance for the poor: Impact on catastrophic and out-ofpocket health expenditures in Mexico. European Journal of Health Economics 11: 437-447.

Ghislandi, Simone, Wanwiphang Manachotphong and Viviana M.E. Perego. 2013. The impact of Universal Health Coverage on healthcare consumption and risky behaviours: evidence from Thailand. Discussion Paper 2013/3.

Ghosh, Soumitra. 2011. Catastrophic payments and impoverishment due to out-ofpocket health spending. Economic \& Political Weekly 46(47): 63-70.

Gruber, Jonason, N. Hendren and Robert M. Townsend. 2014. The great equalizer: Health care access and infant mortality in Thailand. American Economic Journal: Applied Economics 6(1): 91-107.

International Health Policy Program. 2011. National health accounts, Thailand 19942010. IHPP, Ministry of Public Health, Nonthaburi, Thailand.

King, Gary, Emmanuela Gakidou, Kosuke Imai, Jason Lakin, Ryan T Moore, Clayton Nall, Nirmala Ravishankar, Manett Vargas, Martha María Téllez-Rojo, Juan Eugenio Hernández Ávila, Mauricio Hernández Ávila and Héctor Hernández Llamas. 2009. Public policy for the poor? A randomised assessment of the Mexican universal health insurance programme. Lancet 373: 1447-1454 .

Leive, Adam and Ke Xu. 2008. Coping with out-of-pocket health payments: Empirical evidence from 15 African countries. Bulletin of the World Health Organization 86: 849-856.

Limwattananon, Supon, Sven Neelsen, Owen O'Donnell, Phusit Prakongsai, Viroj Tangcharoensathien, Eddy van Doorslaer and Vuthiphan Vongmongkol. 2015. Universal coverage with supply-side reform: The impact on medical expenditure risk and utilization in Thailand. Journal of Public Economics 121: 79-94.

Limwattananon, Supon, Viroj Tangcharoensathien and Phusit Prakongsai. 2007. Catastrophic and poverty impacts of health payments: results from national household surveys in Thailand. Bulletin of the World Health Organization 85: 600-606.

Limwattananon, Supon, Viroj Tangcharoensathien, Kanjana Tisayaticom, Tawekiat Boonyapaisarncharoen and Phusit Prakongsai. 2012. Why has the universal coverage scheme in Thailand achieved a pro-poor public subsidy for health care? BMC Public Health 12(Suppl 1):S6.

Lindelow, Magnus, Loraine Hawkins and Sutayut Osornprasop. 2012. Government spending and central-local relations in Thailand's health sector. Health, Nutrition and Population (HNP) Discussion Paper, World Bank, Washington, Dc.

Lu, Jui-Fen Rachel and William C. Hsiao. 2003. Does universal health insurance make health care unaffordable? Lessons from Taiwan. Health Affairs 22(3) : 77-88.

Miller, Grant, Diana Pinto and Marcos Vera-Hernández. 2013. Risk protection, service use and health outcomes under Colombia's Health Insurance Program for the Poor. American Economic Journal: Applied Economics 5(4): 61-91.

Mills, Anne, Mariam Ally, Jane Goudge, John Gyapong and Gemini Mtei. 2012. Progress towards universal coverage: The health systems of Ghana, South Africa and Tanzania. Health Policy and Planning 27(Supplement 1): i4-i12.

Minh, Hoang Van, Nicola Suyin Pocock, Nathorn Chaiyakunapruk, Chhea Chhorvann, Ha Anh Duc, Piya Hanvoravongchai, Jeremy Lim, Don Eliseo Lucero-Prisno III, Nawi Ng, Natalie Phaholyothin, Alay Phonvisay, Kyaw Min Soe and Vanphanom Sychareun. 2014. Progress toward universal health coverage in ASEAN. Global Health Action 7: 25856. 
Moreno-Serra, Rodrigo and Peter Smith. 2015. Broader health coverage is good for the nation's health: Evidence from country level panel data. Journal of the Royal Statistical Society. 178(Part 1): 101-124.

NaRanong, Viroj and Anchana NaRanong. 2006. Universal health care coverage: Impacts of the 30-Baht Health-Care Scheme on the poor in Thailand. TDRI Quarterly Review 21(3): 3-10.

Panpiemras, Jirawat, Thitima Puttitanun, Krislert Samphantharak and Kannika Thampanishvong. 2011. Impact of universal health care coverage on patient demand for health care services in Thailand. Health Policy 103: 228-235.

Pieters, Hannah, Daniele Curzi, Alessandro Olper and Jo Swinnen. 2014. Political reforms and food security. Working Paper prepared for the 3rd AIEAA Conference Feeding the Planet and Greening Agriculture.

Prakongsai, Phusit, Supon Limwattananon and Viroj Tangcharoensathien. 2015. The equity impact of the universal coverage policy: Lessons from Thailand. In Kara Hanson and Dov Chernichovsky (Eds): Innovations in Health System Finance in Developing and Transitional Economies. Emerald Group Publishing Limited, pp. 5781.

Quast, Troy, Gonzalez, Fidel. 2016. Sex Work Regulation and Sexually Transmitted Infections in Tijuana, Mexico. Health Economics, Online first.

Rannan-Eliya, Ravi P. and Lankani Sikurajapathy. 2009. Sri Lanka: "Good Practice” in expanding health care coverage. Research Studies Series 3. Institute for Health Policy.

Rosenbaum, Paul R. 2002a. Observational Studies (2nd ed.) New York: Springer.

Rosenbaum, Paul R. 2002b. Covariance adjustment in randomized experiments and observational studies. Statistical Science 17 (3): 286-327.

Sachs, Jeffrey D. 2012. Achieving universal health coverage in low-income settings. Lancet 380 (9845): 944-947.

Somanathan, Aparnaa, and Reem Hafez. 2010. Financing options for the health sector in Tonga. World Bank, Washington, DC.

Somkotra, Tewarit and Leizel P. Lagrada. 2009. Which households are at risk of catastrophic health spending: Experience in Thailand after universal coverage. Health Affairs 28(3): w467-w478.

Stuckler, David, Andrea B Feigl, Sanjay Basu and Martin McKee. 2010. The political economy of universal health coverage. Background paper for the global symposium on health systems research 16-19 November 2010, Montreux, Switzerland.

Towse, Adrian, Anne Mills and Viroj Tangcharoensathien. 2004. Learning from Thailand's health reforms. BMJ 328:103-105.

Wagstaff, Adam and Wanwiphang Manachotphong. 2012. The health effects of universal health care evidence from Thailand. Policy Research Working Paper 6119, The World Bank, Washington, DC.

WHO. 2013. World Health Report - Research for Universal Health Coverage. WHO Press, Geneva, Switzerland.

WHO. 2010. World Health Report - Health systems financing: the path to universal coverage. WHO Press, Geneva, Switzerland.

WHO. 2015. Health Financing Policy Brief $\mathrm{N}^{\circ} 1$ - Raising revenues for health in support of UHC: strategic issues for policy makers. WHO Press, Geneva, Switzerland.

$\mathrm{Xu}, \mathrm{Ke}, \mathrm{David} \mathrm{B}$. Evans, Guido Carrin, Ana Mylena Aguilar-Rivera, Philip Musgrove and Timothy Evans. Protecting households from catastrophic health spending. 2007. Health Affairs 26(4): 972-983.

Yardim, Mahmut Saadi, Nesrin Cilingiroglu and Nazan Yardim. 2010. Catastrophic health 
expenditure and impoverishment in Turkey. Health Policy 94(1): 26-33.

Figure 1: Impact and placebo tests of universal health care coverage in Thailand for aggregate health expenditure variables (main model)

Panel A: Out-of-pocket expenditures as \% of total health expenditures

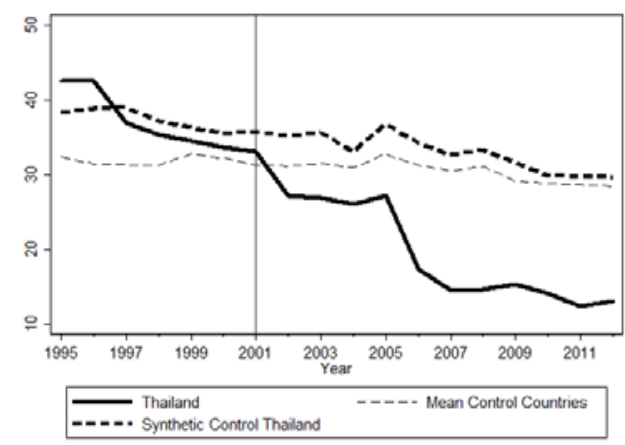

Panel C: Government health expenditures as \% of total health expenditures
Panel B: Placebo Out-of-pocket as \% of total health expenditures

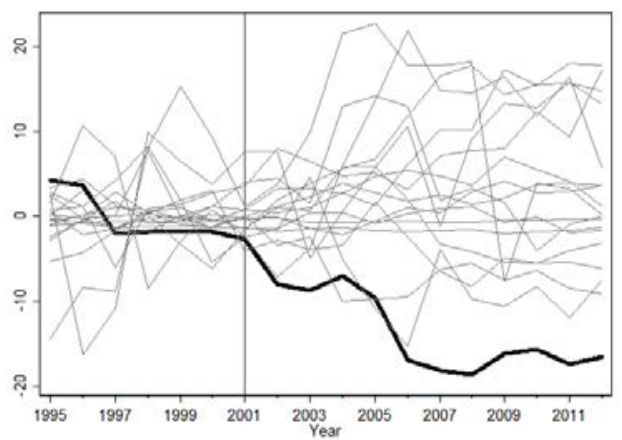

Panel D: Placebo: Government health expenditures as $\%$ of total health expenditures 


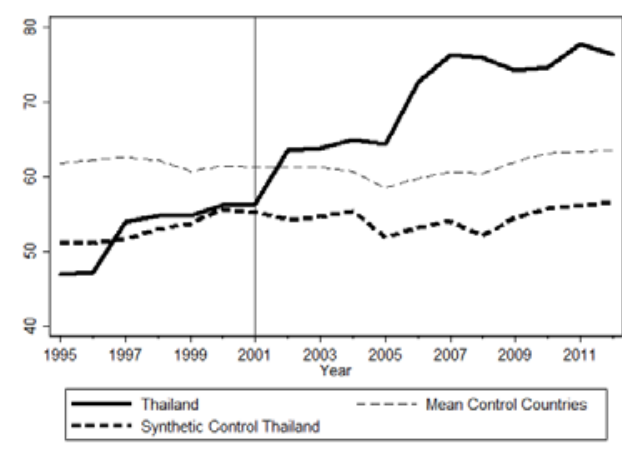

Panel E: Government health expenditures per capita (PPP \$)

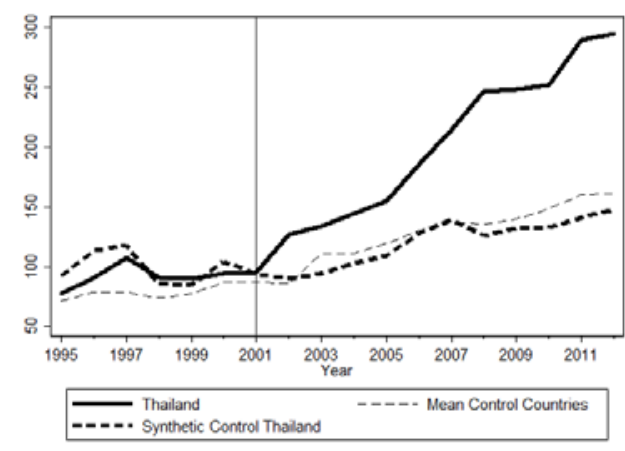

Panel G: Total health expenditures per capita (PPP \$)

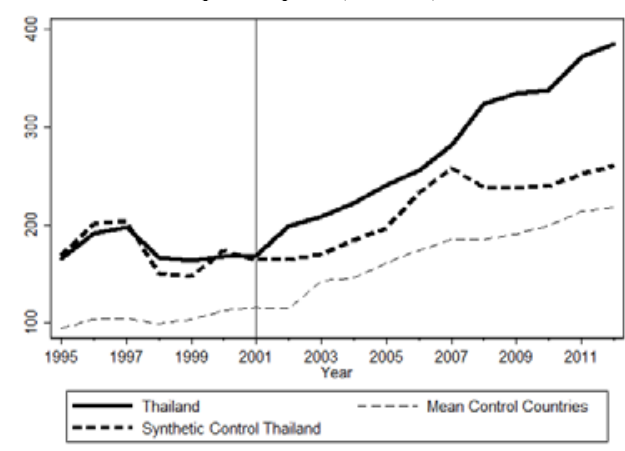

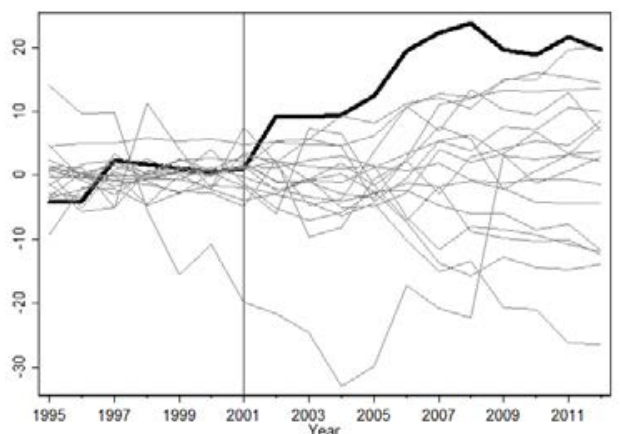

Panel F: Placebo Government health expenditures per capita (PPP \$)

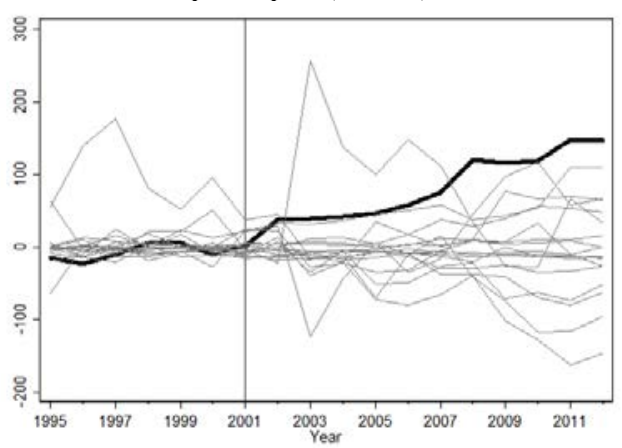

Panel H: Placebo Total health expenditures per capita (PPP \$)

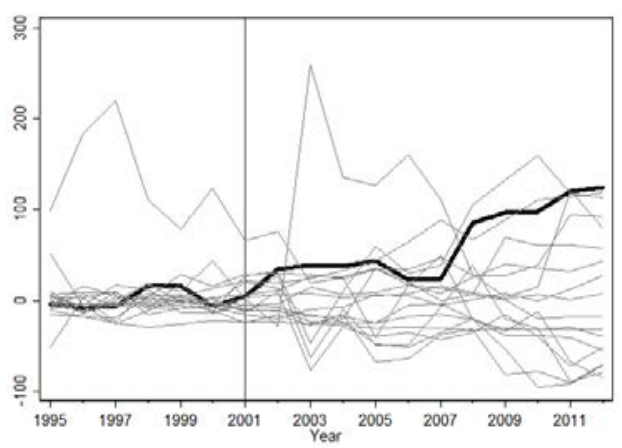

Note: The impact on Thailand is indicated in bold.

Figure 2: Impact and placebo tests of universal health care coverage in Thailand for aggregate health expenditure, economic and child mortality variables (main model)

Panel A: Government health expenditures as \% of total government spending

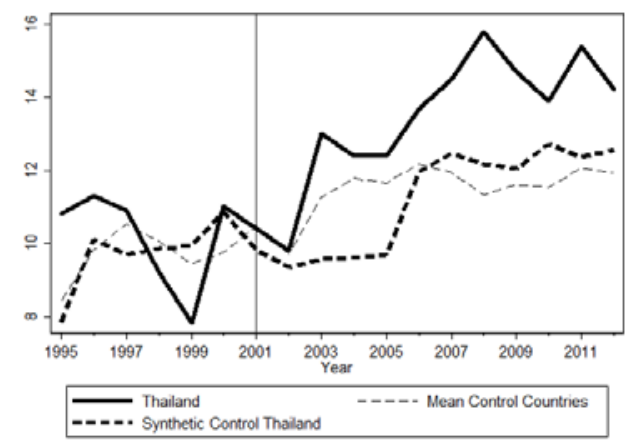

Panel C: Log GDP per capita (constant \$)
Panel B: Placebo Government health expenditures as \% of total government spending

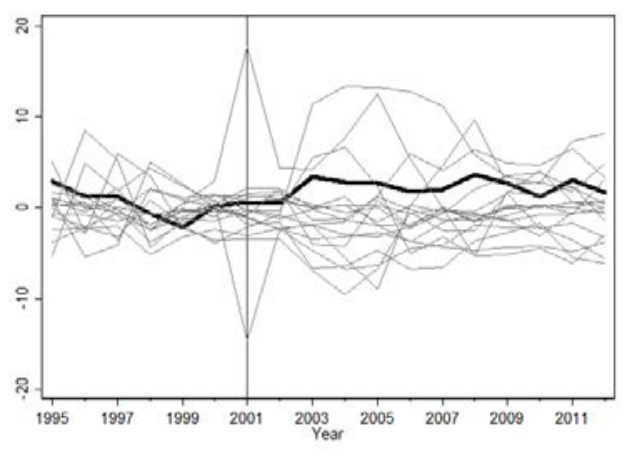

Panel D: Placebo Log GDP per capita (constant \$) 


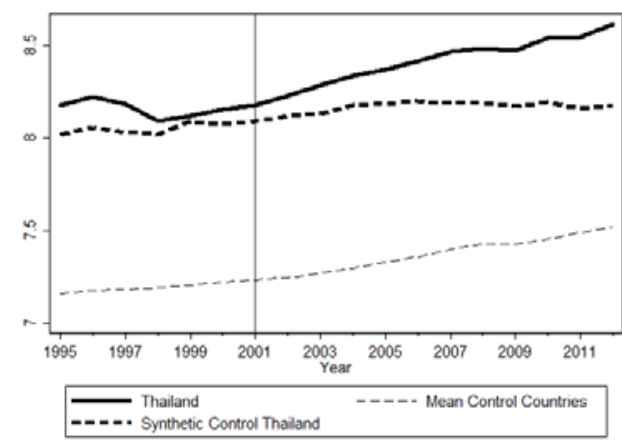

Panel E: Log infant mortality (per 1,000)

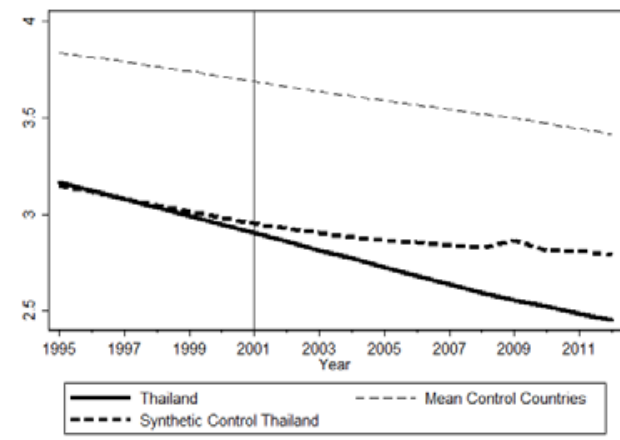

Panel G: Log child mortality (per 1,000)

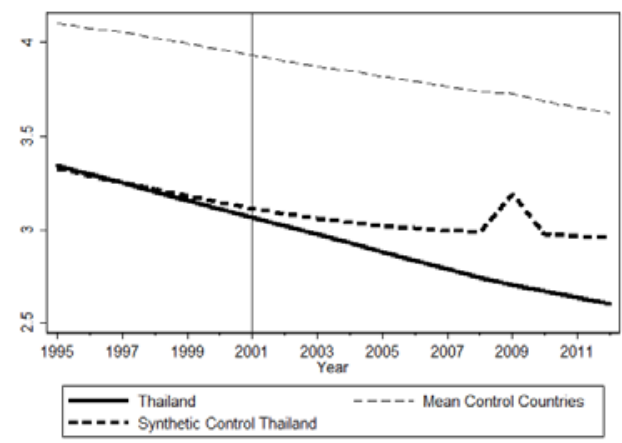

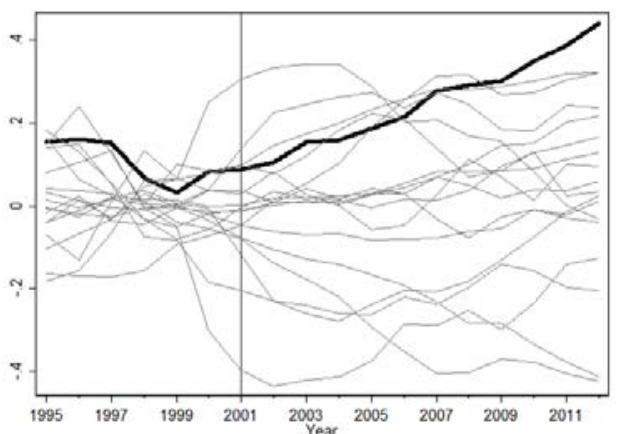

Panel F: Placebo Log infant mortality (per 1,000)

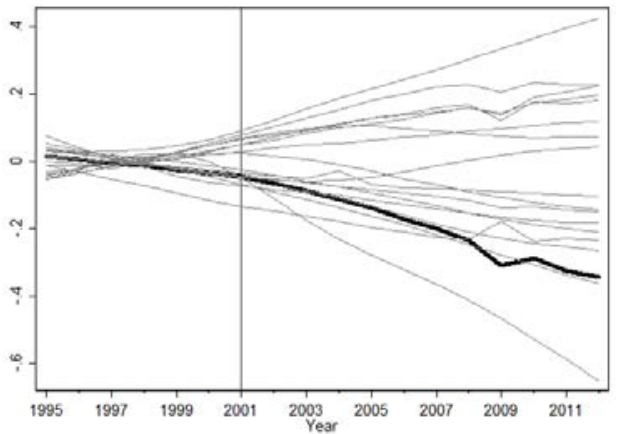

Panel H: Placebo Log child mortality (per 1,000)

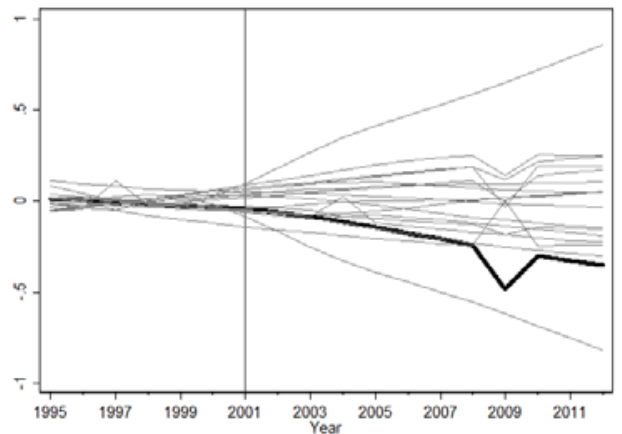

Note: The impact on Thailand is indicated in bold. 


\section{Tables}

Table 1: Pre-treatment balance of outcomes

\begin{tabular}{|c|c|c|c|c|}
\hline \multirow[b]{2}{*}{ Pre-treatment mean of outcomes: } & \multirow{2}{*}{$\begin{array}{c}\text { (1) } \\
\text { Thailand }\end{array}$} & \multirow{2}{*}{$\begin{array}{c}\text { (2) } \\
\text { Controls }\end{array}$} & \multicolumn{2}{|c|}{$\begin{array}{l}\text { (3) (4) } \\
\text { Synthetic } \\
\text { Control }\end{array}$} \\
\hline & & & $\begin{array}{l}\text { Main } \\
\text { Model }\end{array}$ & $\begin{array}{c}\text { Basic } \\
\text { Model }\end{array}$ \\
\hline Out-of-pocket as \% of total health expenditures & 37.60 & 31.96 & 37.55 & 37.61 \\
\hline Government health expend.as \% of total health expenditures & 52.35 & 61.89 & 52.77 & 52.36 \\
\hline Government health expenditures per capita (PPP \$) & 91.77 & 77.91 & 99.85 & 91.74 \\
\hline Total health expenditures per capita (PPP \$) & 175.57 & 103.26 & 174.54 & 175.54 \\
\hline Government health expenditures as \% of total government spending & 10.17 & 9.67 & 9.72 & 10.16 \\
\hline Log GDP per capita (constant \$) & 8.16 & 6.87 & 8.05 & 8.08 \\
\hline Log infant mortality (per 1,000 ) & 3.06 & 3.78 & 3.07 & 3.06 \\
\hline Log child mortality (per 1,000) & 3.23 & 4.04 & 3.24 & 3.24 \\
\hline
\end{tabular}

Note: The pre-treatment outcomes are averaged over the six-year period (1995-2000) prior to the introduction of UHC. Averages are presented for Thailand, for the set of 17 control countries, and the synthetic "Thailands" used in the analysis. A separate synthetic Thailand is estimated for each outcome. 
Table 2: The impact of universal health care coverage in Thailand using synthetic control methods

\begin{tabular}{|c|c|c|c|c|c|c|c|}
\hline (1) & (2) & (3) & (4) & (5) & (6) & (7) & (8) \\
\hline $\begin{array}{l}\text { Out-of- } \\
\text { pocket as \% } \\
\text { of total } \\
\text { health } \\
\text { expend. }\end{array}$ & $\begin{array}{l}\text { Gov't health } \\
\text { expend. as } \\
\text { \% of total } \\
\text { health } \\
\text { expend. }\end{array}$ & $\begin{array}{l}\text { Gov't } \\
\text { health } \\
\text { expend. } \\
\text { per } \\
\text { capita } \\
\text { (PPP \$) }\end{array}$ & $\begin{array}{c}\text { Total } \\
\text { health } \\
\text { expend. } \\
\text { per capita } \\
\text { (PPP \$) }\end{array}$ & $\begin{array}{l}\text { Gov't } \\
\text { health } \\
\text { expend. } \\
\text { as \% of } \\
\text { total gov't } \\
\text { spend. }\end{array}$ & $\begin{array}{c}\text { Log GDP } \\
\text { per capita } \\
\text { (constant } \\
\$)\end{array}$ & $\begin{array}{c}\text { Log } \\
\text { infant } \\
\text { mortal } \\
\text { ity } \\
\text { (per } \\
1,000)\end{array}$ & $\begin{array}{c}\text { Log } \\
\text { child } \\
\text { mortality } \\
\text { (per } \\
1,000)\end{array}$ \\
\hline
\end{tabular}

Panel A: Main model (Matching on pre-treatment dependent variable, other outcomes, and demographic controls)

\begin{tabular}{lcccccccc} 
Impact & -12.98 & 15.54 & 78.98 & 60.83 & 2.16 & 0.25 & -0.19 & -0.21 \\
Pseudo p-value & 0.11 & 0.17 & 0.11 & 0.11 & 0.28 & 0.28 & 0.11 & 0.11 \\
\hline Panel B: Basic Model (Matching & on & pre-treatment & dependent & variable) & & & & \\
Impact & -15.47 & 17.70 & 53.65 & 28.20 & 1.32 & 0.22 & -0.21 & -0.23 \\
Pseudo p-value & 0.11 & 0.11 & 0.11 & 0.33 & 0.33 & 0.28 & 0.11 & 0.11 \\
\hline
\end{tabular}

Note: Impact is defined as the average difference between the post-treatment outcomes for Thailand and the synthetic "Thailands", averaged over twelve post-treatment years. A separate synthetic Thailand is estimated for every outcome. 
Table 3: The impact of universal health care coverage in Thailand using panel regressions

\begin{tabular}{|c|c|c|c|c|c|c|c|}
\hline $\begin{array}{c}\text { Out-of- } \\
\text { pocket } \\
\text { as \% of } \\
\text { total } \\
\text { health } \\
\text { expend. }\end{array}$ & $\begin{array}{c}\text { Gov't } \\
\text { health } \\
\text { expend. } \\
\text { as \% of } \\
\text { total } \\
\text { health } \\
\text { expend. }\end{array}$ & $\begin{array}{c}\text { Gov't } \\
\text { health } \\
\text { expend. } \\
\text { per } \\
\text { capita } \\
\text { (PPP \$) }\end{array}$ & $\begin{array}{c}\text { Total } \\
\text { health } \\
\text { expend. } \\
\text { per } \\
\text { capita } \\
\text { (PPP \$) }\end{array}$ & $\begin{array}{c}\text { Gov't } \\
\text { health } \\
\text { expend. } \\
\text { as \% of } \\
\text { total } \\
\text { gov't } \\
\text { spend. }\end{array}$ & $\begin{array}{c}\text { Log GDP } \\
\text { per } \\
\text { capita } \\
\text { (constant } \\
\$)\end{array}$ & $\begin{array}{c}\text { Log } \\
\text { infant } \\
\text { mortality } \\
\text { (per } \\
1,000 \text { ) }\end{array}$ & $\begin{array}{c}\text { Log child } \\
\text { mortality } \\
\text { (per } \\
1,000)\end{array}$ \\
\hline
\end{tabular}

\begin{tabular}{lccccccccc}
\hline Panel A: Country and time fixed effects plus demographic covariates (unweighted) & \multicolumn{1}{c}{} \\
Impact & $-15.79^{*}$ & $18.17^{*}$ & $56.24^{*}$ & $32.29^{*}$ & 1.49 & 0.05 & $-0.15^{*}$ & $-0.13^{*}$ \\
& $(1.28)$ & $(1.46)$ & $(14.91)$ & $(14.66)$ & $(0.93)$ & $(0.04)$ & $(0.04)$ & $(0.05)$ \\
$\mathrm{N}$ & 324 & 324 & 324 & 324 & 324 & 324 & 324 & 324 \\
\hline
\end{tabular}

Panel B: Country and time fixed effects plus demographic covariates (using synthetic control weights corresponding to main model Panel A of Table 2)

\begin{tabular}{lcccccccc} 
Impact & $-9.04^{*}$ & 12.75 & $68.46^{*}$ & 48.45 & 1.26 & $-0.09 *$ & $-0.15+$ & -0.15 \\
& $(2.25)$ & $(6.97)$ & $(20.22)$ & $(26.77)$ & $(1.04)$ & $(0.00)$ & $(0.04)$ & $(0.05)$ \\
Nr. of control countries & 4 & 3 & 3 & 4 & 4 & 1 & 2 & 2 \\
$\mathrm{~N}$ & 90 & 72 & 72 & 90 & 90 & 36 & 54 & 54 \\
\hline
\end{tabular}

Panel C: Country and time fixed effects plus demographic covariates (using synthetic control weights corresponding to basic model Panel B of Table 2)

\begin{tabular}{lcccccccc} 
Impact & $-14.96^{*}$ & $17.59 *$ & $52.13^{*}$ & 31.54 & 1.41 & $0.13^{*}$ & -0.07 & -0.06 \\
& $(1.58)$ & $(1.71)$ & $(15.97)$ & $(18.67)$ & $(0.91)$ & $(0.02)$ & $(0.06)$ & $(0.06)$ \\
Nr. of control countries & 17 & 17 & 17 & 17 & 17 & 2 & 17 & 17 \\
$\mathrm{~N}$ & 324 & 324 & 324 & 324 & 324 & 54 & 324 & 324 \\
\hline Note: Standard errors are clustered at the & country level, * p-value & $0.05,+\mathrm{p}-\mathrm{value} 0.10$ & & & &
\end{tabular}

Note: Standard errors are clustered at the country level, * p-value $0.05,+$ p-value 0.10 . 